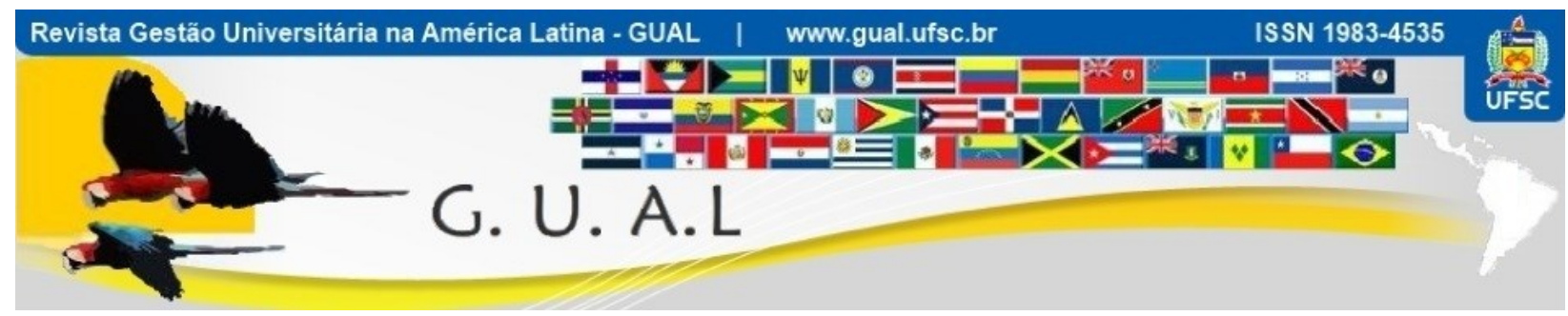

DOI: http://dx.doi.org/10.5007/1983-4535.2016v9n1p60

\title{
O CURSO DE ADMINISTRAÇÃO DA UNIVERSIDADE FEDERAL DE SANTA CATARINA - O PERFIL DOS PROVÁVEIS FORMANDOS
}

\section{THE BUSINESS ADMINISTRATION MAJOR OF THE FEDERAL UNIVERSITY OF SANTA CATARINA: THE GRADUATES' PROFILES}

Irineu Manoel de Souza, Doutor Universidade Federal de Santa Catarina - UFSC irineu.manoel@ufsc.br

Flora Moritz da Silva, Doutoranda Universidade Federal de Santa Catarina - UFSC

floramds@gmail.com

Tássia Grudtner Basílio, Mestranda Universidade Federal de Santa Catarina - UFSC tassiabasilio@gmail.com

Thalita Bez Batti de Souza, Mestranda Universidade do Estado de Santa Catarina - UDESC thalitabbs@.gmail.com

Recebido em 14/março/2014

Aprovado em 11/outubro/2015

Sistema de Avaliação: Double Blind Review

Esta obra está sob uma Licença Creative Commons Atribuição-Uso. 


\title{
RESUMO
}

No Brasil, o curso de Graduação em Administração é o mais buscado pelos estudantes que pretendem ingressar no Ensino Superior. Com isso, está ocorrendo considerável aumento da disputa por vagas no mercado de trabalho, exigindo novas habilidades do administrador. Desta forma, o objetivo deste estudo é analisar o perfil profissional dos prováveis formandos do curso de Graduação em Administração da UFSC nos semestres 2013/2, 2014/1 e 2014/2, para conhecer suas aspirações após a formatura, suas habilidades e a forma que estão inseridos atualmente no mercado de trabalho, sendo relevante no âmbito da Gestão Universitária para refletir sobre os currículos e compreender as áreas de maior demanda para pós-graduação em Administração. Os dados foram coletados por meio de questionários posteriormente tabulados e analisados por meio de medidas estatísticas, utilizando amostragem não probabilística, atingindo $74 \%$ da população total. Os resultados indicam que a maioria dos acadêmicos pesquisados (78\%) já está inserida no mercado de trabalho. A remuneração predominante desses potenciais formandos compreende a faixa de um a dois salários mínimos. Constatou-se que a maioria dos pesquisados pretende continuar seus estudos em nível de pós-graduação. A pesquisa ainda apresenta correlações relevantes, desde a relação entre turno e vínculo profissional até a verificação de diferenças na média de remuneração por gêneros.

Palavras-chave: Carreira. Administração. Universidade. Mercado de trabalho.

\begin{abstract}
In Brazil the major in business administration is the most sought by students who wish to enter in colllege. Therefore the competition for jobs in this area is increasing and new management skills are required. This study aims to analyze the professional profile of UFSC business administration major of who were supposed to graduate in 2013/2, 2014/1 and 2014/2. These profiles will comprehend their carrier aspirations, their managements skills and how they are inserted in their carrier field. Additionally, these data will be used to analyze the social function of the university, thinking the way to improve the courses syllabus to prepare better the student to graduate degree. Data were collected through questionnaires and were analyzed using statistical tests, using non-probability sampling, reaching $74 \%$ of the studied population. The results indicate that the majority of surveyed students $(78 \%)$ is already in the job market. Most of these students earn within one and two minimum wages. It was found that the majority of respondents want to continue their studies at graduate degree. This study also shows significant correlations between "shift" and "professional ties" to the verification of differences in average pay by gender.
\end{abstract}

Key-words: Career. Business Administration. University. Labor Market. 


\section{INTRODUÇÃO}

A sociedade contemporânea apresenta-se como um ambiente sociocultural, econômico, tecnológico e educacionalmente transformado: a era do conhecimento e da informação, formada por cenários complexos e contraditórios, especialmente no que se refere às transformações no mundo do trabalho.

Nesse contexto, verifica-se um acréscimo no número de instituições de ensino superior (IES) no Brasil. Segundo dados do Ministério da Educação (MEC) em 2010, havia 1.805 cursos de Administração (CFA, 2011). Com isso, está ocorrendo considerável aumento da disputa por vagas no mercado de trabalho. A fim de enfrentar essa concorrência, as IESs necessitam inovar na formação de seus alunos. Destaca-se que Administração é o curso de graduação mais procurado no país (MEC, 2015).

O presente estudo visa conhecer o perfil profissional dos prováveis formandos dos anos de 2013/2, 2014/1 e 2014/2 do curso presencial de Graduação em Administração da Universidade Federal de Santa Catarina (UFSC). O interesse por esse tema de pesquisa decorre da alta competitividade existente no mercado de trabalho e da exigência de busca constante de aperfeiçoamento profissional. Também é desejável identificar se a universidade está formando os profissionais de Administração que atendam as necessidades da sociedade do conhecimento, sendo relevante no âmbito da Gestão Universitária, para refletir sobre os currículos e compreender as áreas de maior demanda para pós-graduação.

Com o intuito de atingir os objetivos da pesquisa, foi realizada uma amostragem nãoprobabilística com base em uma listagem com os nomes dos prováveis formandos do curso de Administração, fornecida pelo Departamento de Ciências de Administração da UFSC.

A pesquisa realizada permitiu traçar o perfil dos estudantes que provavelmente concluiriam o curso de Administração nos semestres de 2013/2, 2014/1 e 2014/2, também levantando variáveis relacionadas a atitudes e percepções, como o grau de satisfação relativo à área em que se está trabalhado, os planos de estudos, quando existentes, após o término do curso, inclusive a área de carreira a ser seguida. Aos estudantes que no momento não estão exercendo atividades profissionais, que representam um quarto da amostra, buscou-se compreender o motivo predominante de não estar trabalhando.

A partir destas informações, aplicou-se análises estatísticas, possibilitando refletir sobre algumas correlações, que vão desde a relação entre turno e tipo de vínculo com a 
empresa até a verificação de diferenças na média de remuneração entre homens e mulheres, contribuindo para a análise e para o alcance dos objetivos da pesquisa.

Definiu-se como objetivo geral da presente pesquisa: identificar e analisar o perfil profissional dos prováveis formandos do curso de Graduação em Administração da UFSC, nos semestres 2013/2, 2014/1 e 2014/2. A fim de atingir tal meta, foram definidos os seguintes objetivos específicos: identificar a atual colocação do público-alvo no mercado de trabalho; identificar nível salarial; conhecer as experiências e/ou qualificações que diferenciem seu currículo, tais como línguas, outras graduações, pós-graduação, e; identificar suas pretensões profissionais após o término do curso.

\section{EDUCAÇÃO SUPERIOR BRASILEIRA}

As IESs brasileiras, segundo a legislação, estão organizadas da seguinte forma: Universidades; Universidades Especializadas; Centros Universitários; Centros Universitários Especializados; Faculdades Integradas; Faculdades; Institutos Superiores ou Escolas Superiores; e Centros de Educação Tecnológica (SILVA, FINGER e VITAL, 2008).

Além disso, as instituições podem ser públicas - mantidas e administradas pelo Poder Público, podendo ser federais, estaduais ou municipais; - ou privadas, em que são mantidas e administradas por pessoas físicas ou jurídicas de direito privado, com ou sem fins lucrativos.

Em relação aos cursos de ensino superior, após a conclusão do ensino médio ou equivalente, o sistema educacional brasileiro oferece para a continuidade dos estudos superiores os cursos sequenciais, com até dois anos de duração, os cursos de formação tecnológica, com dois ou três anos de duração, e os cursos de graduação, a maioria com quatro anos de duração, havendo, porém, cursos com cinco ou seis anos de duração.

O curso de Administração analisado no presente trabalho corresponde a um curso de Graduação, com duração de nove semestres, inserido em uma universidade pública, a UFSC.

Segundo o Censo 2011 realizado pelo MEC, havia 30.420 cursos de graduação no Brasil, sendo que 96,6\% deles (29.376) são da modalidade presencial, e 3,4\% (1.044) da modalidade a distância (INEP, 2012a).

\subsection{GRADUAÇÃO EM ADMINISTRAÇÃO}

De acordo com as Diretrizes Curriculares Nacionais os cursos de graduação em administração devem ensejar, como perfil desejado do formando, capacitação e aptidão para 
compreender as questões científicas, técnicas, sociais e econômicas da produção e de seu gerenciamento, observados níveis graduais do processo de tomada de decisão. Além disso, visa desenvolver o gerenciamento qualitativo e adequado, revelando a assimilação de novas informações e apresentando flexibilidade intelectual e adaptabilidade contextualizada no trato de situações diversas, presentes ou emergentes, nos vários segmentos do campo de atuação do administrador (SOUZA, 2013).

As citadas diretrizes curriculares orientam ainda que os referidos cursos devam possibilitar a formação profissional que revele, pelo menos, as seguintes competências e habilidades: estratégia e tomada de decisão; processos de negociação e nas comunicações interpessoais ou intergrupais; modo crítico e criativo diante dos diferentes contextos organizacionais e sociais; qualidade e implicações éticas do seu exercício profissional; capacidade de transferir conhecimentos da vida e da experiência cotidianas para o ambiente de trabalho e do seu campo de atuação profissional, e projetos em organizações. Em relação aos projetos pedagógicos os cursos de graduação em Administração deverão contemplar seguintes conteúdos: Conteúdos de Formação Básica; Conteúdos de Formação Profissional; Conteúdos de Estudos Quantitativos e suas Tecnologias; e Conteúdos de Formação Complementar, conclui o citado autor.

Cabe destaque para a exigência do Conselho Nacional de Educação (CNE) da formação dos acadêmicos dos cursos de graduação em administração em estudos opcionais, pois é por meio dessa diretriz que é possibilitada a formação do administrador em caráter transversal e interdisciplinar.

Além dos diversos enfoques no currículo do curso orientados pelas Diretrizes Curriculares Nacionais, a graduação em Administração, segundo o MEC, foi o curso com maior número de inscrições entre os estudantes participantes do Sistema de Seleção Unificada (SISU) na edição de 2014. Conforme pode ser visualizado no Quadro 1, foram 192.582 alunos inscritos para o curso de Administração, seguido de 191.107 alunos inscritos no curso de Direito e 176.876 no curso de Medicina. 


\begin{tabular}{|l|c|c|c|}
\hline \multicolumn{4}{|c|}{ Inscrições por curso } \\
\hline \multicolumn{1}{|c|}{ Curso } & Inscrições & Vagas & Relação (\%) \\
\hline Medicina & 176.876 & 2.925 & 60,47 \\
\hline Direito & 191.107 & 4.724 & 40,45 \\
\hline Engenharia civil & 106.311 & 3.053 & 34,82 \\
\hline Administração & 192.582 & 6.135 & 31,39 \\
\hline Educação física & 84.125 & 3.024 & 27,82 \\
\hline
\end{tabular}

Quadro 1 Inscrições por curso - SISU 2014.

Fonte: MEC, 2015.

$\mathrm{Na}$ edição mais recente do SISU, de 2015, manteve-se a maior procura dos inscritos pelo curso de Administração, segundo informa o Instituto Nacional de Estudos e Pesquisas Educacionais Anísio Teixeira (INEP), conforme se vê no Quadro 2.

\begin{tabular}{|c|c|c|c|c|}
\hline Ordem & Curso & Inscriçöes & Vagas & Candidato $x$ Vaga \\
\hline 1 & ADMINISTRAÇÃO & 312.991 & 7.541 & 41,51 \\
\hline 2 & DIREITO & 262.255 & 5.741 & 45,68 \\
\hline 3 & PEDAGOGIA & 249.348 & 8.338 & 29,91 \\
\hline 4 & MEDICINA & 237.267 & 3.758 & 63,14 \\
\hline
\end{tabular}

Quadro 2 Inscrições por curso - SISU 2015.

Fonte: G1, 2015.

\subsubsection{O Curso de Graduação em Administração da UFSC}

No curso de graduação em Administração da UFSC, cuja estruturação segue as orientações do CNE, a cada semestre, 90 alunos são aprovados no vestibular para ingresso, sendo 45 para o turno matutino e 45 para o turno noturno. Devido a desistências, transferências, trancamentos de matrículas, dentre outros fatores, pouco mais de 50 alunos têm se formado a cada semestre.

A universidade é reconhecida como uma das melhores do país, estando em $7^{\circ}$ lugar no Ranking Universitário da Folha de São Paulo (RUF, 2013). O curso de Administração também é reconhecido como um dos melhores do Brasil, tendo obtido nota máxima no ENADE em 2012. De acordo com o relatório do INEP (2012b), a média das notas da prova do ENADE sobre conhecimentos específicos dos formandos de Administração da UFSC foram mais altas que a média do Brasil, sendo 45,7 e 31,9 respectivamente. 
Segundo o Plano Estratégico na página do Departamento de Ciências da Administração (2013, s/p.), a missão do Departamento é: “Construir e socializar o saber amplo sobre as organizações e sua gestão, por meio da valorização dos potenciais humanos e da otimização dos recursos ambientais e institucionais, em benefício da sociedade".

\subsection{O PERFIL DO ADMINISTRADOR}

As transformações ocorridas nos ambientes organizacionais com a transição da Era Industrial para a Era do Conhecimento exigem uma mudança substancial do perfil dos futuros administradores. O desenvolvimento das tecnologias da informação e da comunicação e o acirramento da competição em escala global são fenômenos que orientam para novas competências e habilidades dos administradores.

Nas últimas décadas as organizações têm aprendido que o sucesso do gerenciamento dos negócios não depende apenas da administração de sua estrutura, da administração da rentabilidade de cada empresa ou grupo de produtos, mas, sobretudo da identificação e desenvolvimento de suas capacidades essenciais. Basicamente são competências que devem servir de critério nas organizações atuais, os parâmetros estratégicos de decisão sobre quais produtos e quais mercados participar, onde investir e onde desinvestir. Estas competências, para serem adquiridas e mantidas, dependem de pessoas especializadas trabalhando em equipe. O funcionamento destas equipes depende de pessoas que, além de sua especialização, possuam responsabilidade e poder de comunicação (PRAHALAD e HAMEL, 1990).

Nesse contexto, os governos de países industrializados dirigem mensagens transformadoras às instituições de ensino de forma direta e explícita, principalmente por meio de processos de avaliação governamental. Trata-se de um movimento de profundidade, que testa a utilidade da formação promovida pelas instituições, frente ao seu custo econômico e social. Na maioria desses países, a avaliação, integra-se no desenvolvimento do ato de ensino e toma a forma de um controle contínuo (ROPÉ e TANGUY, 1997).

No Brasil o MEC, por meio do CNE tem priorizado reformas, embora tímidas ainda no processo de avaliação institucional das universidades brasileiras.

O Conselho Federal de Administração (CFA) realizou em 2011 uma pesquisa a fim de definir o perfil, formação, atuação e oportunidades de trabalho do profissional de administração. A pesquisa foi realizada em com administradores de todo o país, formados entre 2000 e 2011. A média de idade é de 39,3 anos, a maior parte é do sexo masculino, 
trabalha em empresas de grande porte (serviços e indústria), possui carteira assinada e é registrado em seu CRA (Conselho Regional de Administração) correspondente (CFA, 2011).

Além disso, a pesquisa mostrou que a maioria dos pesquisados são casados e possuem dependentes, formados em universidades particulares, tem especialização em alguma área de administração e ocupa cargos de gerência. Em relação à renda individual do Administrador, a pesquisa identificou que a maior incidência de respostas ficou na faixa entre 3,1 e 10,0 salários-mínimos. Considerando-se os pontos médios das faixas e o número de respondentes em cada uma, a renda média aproximada do Administrador foi de 9,7 salários-mínimos.

O Conselho Regional de Administração de São Paulo (CRA-SP) indica que:

A carreira de Administração apresenta uma peculiaridade em relação às demais profissões: assim como as relações econômicas, ela é dinâmica. Constantemente agrega novos campos de atuação ao seu escopo, o que dá maior flexibilidade ao currículo. Assim, todo profissional em Administração recebe uma formação básica e uma complementação específica, garantindo-lhe uma visão global e uma ênfase em um campo particular: planejamento, finanças, comércio exterior, marketing, recursos humanos, informática, logística e administração pública (SILVA, FINGER e VITAL, 2008, p.04)

De acordo com o artigo $3^{\circ}$ do Decreto que regulamenta a profissão (61.934/67), a atividade profissional do Administrador, como profissão, liberal ou não, compreende:

[...] elaboração dos pareceres, relatórios, planos, projetos, arbitragens e laudos, em que se exija a aplicação de conhecimentos inerentes às técnicas de organização; pesquisas, estudos, análises, interpretação, planejamento, implantação, coordenação e controle dos trabalhos nos campos de administração geral, como administração e seleção de pessoal, organização, análise, métodos e programas de trabalho, orçamento, administração de material e financeira, administração mercadológica, administração de produção, relações industriais, bem como outros campos em que estes de desdobrem ou com os quais sejam conexos (CRA-SP, 2013, s/p).

Segundo a pesquisa do CFA (2011), as áreas funcionais de Administração Geral, Financeira, Vendas e Recursos Humanos são as mais demandas, representando $58,82 \%$ do total de respondentes. O CFA (2011) destaca que a área de Recursos Humanos, que vinha decrescendo, apresentou um aumento no índice em relação a 2006: de 6,73\% para 9,46\%.

Outro dado importante retratado na pesquisa supracitada é que a formação do Administrador foi avaliada, pelos próprios administradores, como muito acadêmica e com visão fortemente voltada para o desempenho na área administrativa das empresas; o que reforça a necessidade de reflexão sobre o currículo dos cursos frente ao perfil de seus estudantes/profissionais e a demanda do mercado de trabalho. 


\section{METODOLOGIA}

A partir da caracterização dos tipos de estudos realizada por Mattar (2005), a presente pesquisa consiste em um estudo conclusivo descritivo, com objetivos bem definidos, procedimentos formais, estruturação da pesquisa e do problema de pesquisa. As questões que direcionaram o instrumento de coleta de dados foram elaboradas com base no problema e objetivos de pesquisa já conhecidos. Quanto à natureza das variáveis, é predominantemente quantitativa, pois busca traçar um perfil utilizando dados obtidos de um grande número de respondentes, escalas e análises estatísticas formais.

Em termos de amplitude e profundidade, classifica-se como um levantamento amostral, caracterizado "pela obtenção de dados representativos da população estudada, tanto em termos do número quanto do processo de seleção dos elementos da amostra de pesquisa" (MATTAR, 2005, p. 82). Quanto à dimensão do tempo, a pesquisa é ocasional, pois seus resultados mostram o instantâneo da população estudada, neste caso o perfil dos prováveis formandos dos períodos 2013.2, 2014.1 e 2014.2 do curso presencial de Graduação em Administração da UFSC.

Para determinação da população, utilizou-se dados secundários da UFSC - o departamento do curso forneceu uma listagem com os nomes dos prováveis formandos do período de interesse. Os dados foram coletados por meio de questionários, aplicados dentro do Centro Socioeconômico da UFSC. O método utilizado classifica-se como estruturado não disfarçado, já que as perguntas a todos os elementos pesquisados foram apresentadas exatamente com as mesmas palavras, na mesma ordem e com as mesmas opções de respostas. O instrumento de coleta de dados foi adaptado e passou por pré-teste com indivíduos semelhantes à população-alvo antes de serem aplicados formalmente.

Quanto à forma de aplicação, foram adotados questionários autopreenchíveis, lidos e respondidos pelo pesquisado de forma direta, sem a necessidade do pesquisador, entregues e recolhidos pessoalmente em sala de aula, nas turmas pré-estabelecidas.

A população da pesquisa foi definida como os prováveis formandos (semestres 2013/2, 2014/1 e 2014/2) do curso presencial de Graduação em Administração da UFSC. Foi realizada uma amostragem não-probabilística por acessibilidade, que de acordo com Zikmund (2006), tem como principal característica o fato de que a probabilidade de um determinado membro da população ser escolhido é desconhecida. Foram utilizadas as listas de frequências das seis turmas que fizeram parte da população alvo: as listas da sétima, oitava e nona fase, 
tanto diurno quanto noturno. Dentre os tipos de amostragem não-probabilística descritos por Zikmund (2006), utilizou-se a amostragem por acessibilidade, pois se buscou pesquisar os estudantes que efetivamente estavam frequentando as aulas regularmente. Para Barbetta (2011), as técnicas de amostragem não-aleatórias buscam gerar amostras que, de alguma maneira, representem satisfatoriamente bem a população de onde foram extraídas. Os questionários foram aplicados durante as aulas, obtendo-se ao total, 153 respondentes no período de setembro a outubro de 2013 , totalizando $74 \%$ do público-alvo. Os dados foram tabulados e posteriormente, realizaram-se análises estatísticas.

\section{O PERFIL PROFISSIONAL DOS FORMANDOS EM ADMINISTRAÇÃO}

A análise de dados consiste em transformar em informações úteis os dados brutos obtidos com a etapa de aplicação do instrumento de coleta. Por meio dos dados da pesquisa, foram identificadas características da população respondente aqui relatadas.

Conforme os dados obtidos, há predominância do sexo masculino dentre os formandos do curso de graduação em Administração da UFSC. Dentre os 153 entrevistados, 94 são do sexo masculino, representando $61 \%$ da amostra; e 59 são do sexo feminino.

A idade predominante dos acadêmicos é de 21 a 24 anos de idade, correspondendo, em conjunto, a $60 \%$ do total de entrevistados. Considerando que o curso analisado possui nove semestres, acredita-se que a maioria dos estudantes ingressou na universidade aos 18 anos de idade. Entre 30 e 40 anos se encontra apenas 4\% dos pesquisados. A média de idade dos alunos é de 23,6 anos. A mediana, que consiste no ponto central da distribuição, é 23 anos. A moda, que representa a idade mais comum, é de 21 anos. $\mathrm{O}$ desvio padrão resultou em 4,04 anos, demonstrando relativa dispersão em torno da distribuição. Tal distribuição pode ser observada no Gráfico 1.

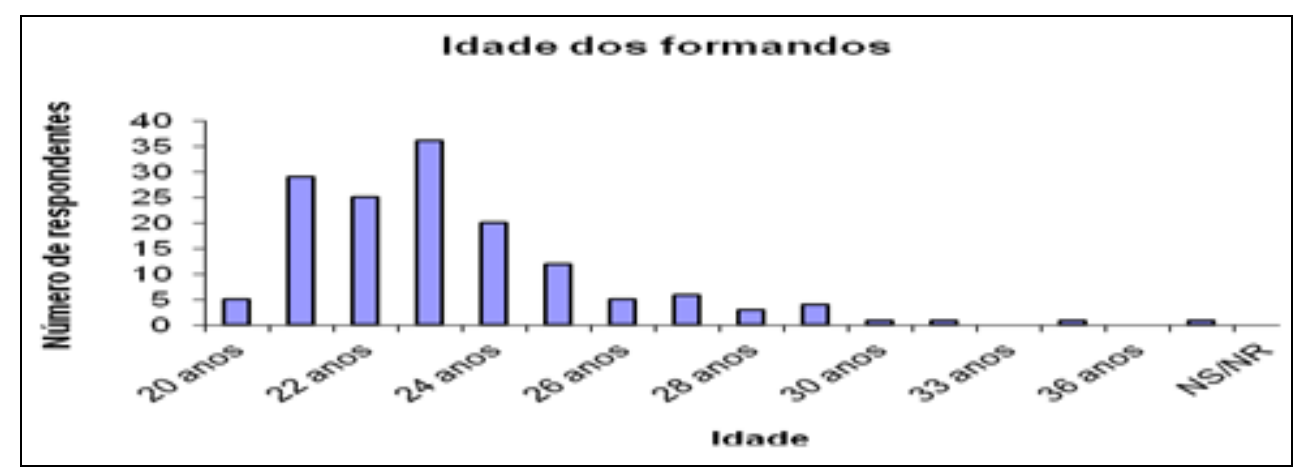

Gráfico 1 Idade dos formandos.

Fonte: Dados primários. 
O maior número de retorno de questionários ocorreu em relação aos acadêmicos que estão cursando a sétima fase, correspondendo a 39\% do total de entrevistados. Os formandos de 2013/2, estudantes da nona fase, têm menor representatividade no total de questionários aplicados, com apenas 29\%, como mostra o Quadro 3:

\begin{tabular}{|cccc|}
\hline Frequência & $\begin{array}{c}\text { Frequência } \\
\text { Absoluta }\end{array}$ & $\begin{array}{c}\text { Frequência } \\
\text { Acumulada } \\
\text { Relativa }\end{array}$ \\
\hline $7^{\text {a Fase }}$ & 59 & 59 & $39 \%$ \\
$8^{\text {a Fase }}$ & 49 & 108 & $32 \%$ \\
$9^{\text {a Fase }}$ & 44 & 152 & $29 \%$ \\
Outras Fases & 1 & 153 & $1 \%$ \\
\hline Total & $\mathbf{1 5 3}$ & & $\mathbf{1 0 0 \%}$ \\
\hline
\end{tabular}

Quadro 3 Fase.

Fonte: Dados primários.

A maior parte dos entrevistados está matriculada no curso de Administração no período noturno, totalizando $60 \%$ dos respondentes. Este fato é observado na realização da matrícula, em que ocorre falta de vagas para muitas disciplinas do período noturno, apesar do concurso vestibular inicialmente abrir 45 vagas para cada período. Acredita-se que este fato seja agravado nas últimas fases do curso, em que há um maior número de alunos trabalhando ou estagiando durante o dia, e sem outra escolha a não ser estudar à noite.

Grande parte dos entrevistados (41\%) pretende finalizar o curso de graduação no final de 2014 , contra $24 \%$ que almeja fazê-lo no início de 2014 e $28 \%$ no segundo semestre de 2013. Isso é associado com a porcentagem respectiva de respondentes em cada fase, exposta no Quadro 3. Pode-se inferir que poucos pretendem adiar a data de conclusão do curso, sendo a porcentagem de respondentes que estão na nona fase $(29 \%)$ quase a mesma dos que finalizarão o curso em 2013/2 (28\%).

Conforme se observa no Gráfico 2, a maioria dos respondentes (55\%) mora com a família. Seguem-se os que residem com amigos, normalmente dividindo apartamentos, com 19\%. Apenas 14\% da amostra mora sozinha e 9\% mora com parceiro (a). Apesar de o estudo ser realizado na UFSC, que recebe estudantes de diversas partes do país, mais da metade dos estudantes do curso reside com a família. Este dado pode confirmar uma tendência que pesquisadores vêm colocando sobre a atual geração jovem: segundo pesquisa da UNESCO (2006), pelo menos 49\% dos jovens brasileiros entre 15 e 29 anos não pensa em deixar a casa dos pais, e dos que saem, 25,5\% retornam. Outra hipótese para o fato seria que, pela 
facilidade de encontrar o curso de Administração, para muitos estudantes pode valer mais estudar em outra faculdade de sua região do que deslocar-se até a UFSC, mesmo considerando o nome da instituição.

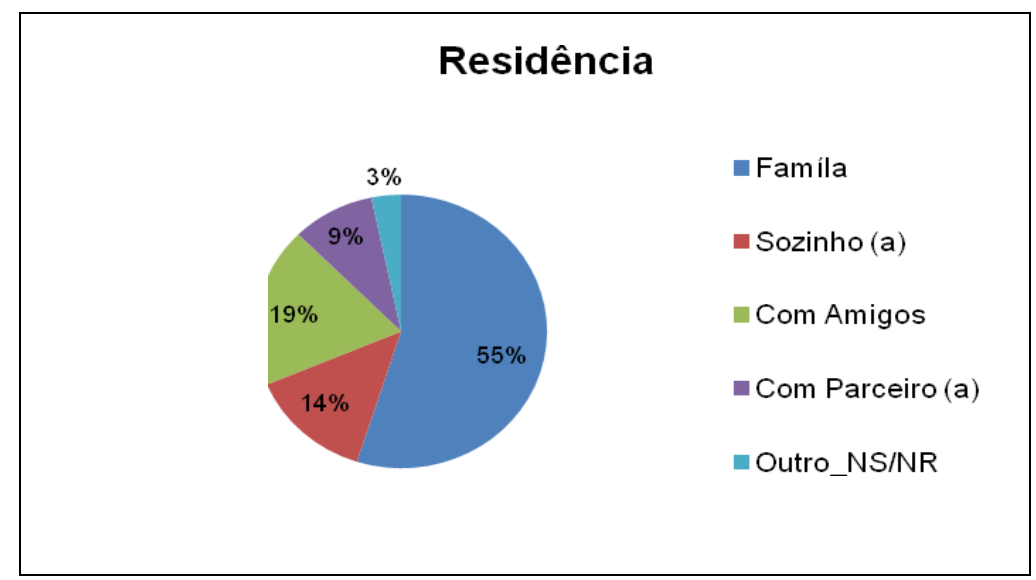

Gráfico 2 Residência.

Fonte: Dados primários.

Quanto à atividade profissional, percebe-se quase a mesma freqüência absoluta dos respondentes que já são funcionários da empresa (46 pessoas, ou 38,33\%) e dos que declaram realizar estágio (45 pessoas, ou 37,5\%), como apresentado no Quadro 4, que expõe dados apenas daqueles que realizam alguma atividade.

No entanto, há um elevado número de formandos que não exerce nenhuma atividade profissional: 33 acadêmicos, ou seja, quase um quarto dos entrevistados (22\%). O principal motivo apresentado para o não exercício de atividades profissionais é a dedicação exclusiva ao curso de graduação, representando $39 \%$ dos respondentes, seguido de $15 \%$ dos que estão se dedicando apenas ao TCC e outros $15 \%$ que estão procurando novos estágios.

Dentre os 120 respondentes que trabalham 39\% indicaram que exercem a sua atividade profissional predominante há menos de um ano; e mais da metade $(68 \%)$ o faz há menos de 2 anos. Entende-se que esse fator decorre principalmente devido à alta rotatividade dos estágios, e ao fato de que, à medida que avançam ao final do curso de graduação, os acadêmicos começam a se inserir no mercado de trabalho como funcionários. O Quadro 4 mostra os vínculos dos entrevistados com as organizações, e o Quadro 5 apresenta a atividade profissional exercida. 


\begin{tabular}{|cccc|}
\hline & $\begin{array}{c}\text { Frequência } \\
\text { Absoluta }\end{array}$ & $\begin{array}{c}\text { Frequência } \\
\text { Acumulada }\end{array}$ & $\begin{array}{c}\text { Frequência } \\
\text { Relativa }\end{array}$ \\
\hline Carteira assinada & 46 & 46 & $38 \%$ \\
Estágio remunerado & 43 & 89 & $36 \%$ \\
Estágio não-remunerado & 2 & 91 & $2 \%$ \\
Bolsa de ensino & 1 & 92 & $1 \%$ \\
Bolsa de pesquisa & 4 & 96 & $3 \%$ \\
Bolsa de extensão & 1 & 97 & $1 \%$ \\
Outro & 23 & 120 & $19 \%$ \\
NS/NR/NA & 0 & 120 & $0 \%$ \\
\hline Total & $\mathbf{1 2 0}$ & & $\mathbf{1 0 0 \%}$ \\
\hline
\end{tabular}

Quadro 4 Vínculo com a empresa (somente quem trabalha).

Fonte: Dados primários.

\begin{tabular}{|cccc|}
\hline & $\begin{array}{c}\text { Frequência } \\
\text { Absoluta }\end{array}$ & $\begin{array}{c}\text { Frequência } \\
\text { Acumulada }\end{array}$ & $\begin{array}{c}\text { Frequência } \\
\text { Relativa }\end{array}$ \\
\hline Bolsista & 7 & 7 & $5 \%$ \\
Funcionário & 46 & 53 & $30 \%$ \\
Estagiário & 45 & 98 & $29 \%$ \\
Não trabalha & 33 & 131 & $22 \%$ \\
Outro & 22 & 153 & $14 \%$ \\
\hline Total & $\mathbf{1 5 3}$ & & $\mathbf{1 0 0 \%}$ \\
\hline
\end{tabular}

Quadro 5 Atividade profissional.

Fonte: Dados primários.

Das 120 pessoas que exercem alguma atividade profissional, 14 (12\%) afirmaram trabalhar e/ou estagiar em mais de um local. As questões a seguir, caracterizando a empresa e o trabalho foram respondidas baseadas na atividade profissional principal do acadêmico.

Quanto ao tipo de organização para qual o acadêmico presta serviço, observa-se uma predominância de empresas privadas, seguida das organizações públicas. Os autônomos correspondem a uma parcela pouco representativa da população, conforme exposto no Quadro 6.

\begin{tabular}{|cccc|}
\hline & $\begin{array}{c}\text { Frequência } \\
\text { Absoluta }\end{array}$ & $\begin{array}{c}\text { Frequência } \\
\text { Acumulada }\end{array}$ & $\begin{array}{c}\text { Frequência } \\
\text { Relativa }\end{array}$ \\
\hline Privada com fins lucrativos & 62 & 62 & $52 \%$ \\
Pública & 35 & 97 & $29 \%$ \\
Sem fins lucrativos & 12 & 109 & $10 \%$ \\
Autônomo & 4 & 113 & $3 \%$ \\
Outro & 7 & 120 & $6 \%$ \\
\hline Total & $\mathbf{1 2 0}$ & & $\mathbf{1 0 0 \%}$ \\
\hline
\end{tabular}

Quadro 6 Tipo de organização - codificada (somente quem trabalha). Fonte: Dados Primários. 
Muitos dos entrevistados exercem atividade profissional em empresas com mais de 1.000 funcionários, como demonstrado no Quadro 7: dentre os 120 respondentes que exercem atividade profissional, 33 acadêmicos (28\%), o fazem em grandes empresas.

\begin{tabular}{|cccc|}
\hline & $\begin{array}{c}\text { Frequência } \\
\text { Absoluta }\end{array}$ & $\begin{array}{c}\text { Frequência } \\
\text { Acumulada }\end{array}$ & $\begin{array}{c}\text { Frequência } \\
\text { Relativa }\end{array}$ \\
\hline Micro-empresa (até 4 pessoas) & 13 & 13 & $11 \%$ \\
Pequeno Porte $(5$ e $<20$ funcionários) & 26 & 39 & $22 \%$ \\
Médio Porte $(20$ e $<100$ funcionários) & 17 & 56 & $14 \%$ \\
Grande Porte $(100$ e $<1000$ funcionários $)$ & 28 & 84 & $23 \%$ \\
Mais de 1000 funcionários & 33 & 117 & $28 \%$ \\
Não se aplica & 2 & 119 & $2 \%$ \\
NS/NR & 1 & 120 & $1 \%$ \\
\hline Total & $\mathbf{1 2 0}$ & & $\mathbf{1 0 0 \%}$ \\
\hline
\end{tabular}

Quadro 7 Tamanho da organização - codificada (somente quem trabalha).

Fonte: Dados primários.

Durante a realização de suas atividades profissionais, a maioria dos formandos $(42 \%)$ executa atividades da área administrativa, como demonstrado no Gráfico 3. A segunda atividade mais realizada é na área financeira, com $17 \%$ das respostas; e a área de educação possui $9 \%$. $\mathrm{Na}$ área de educação estão inclusas, dentre outras, algumas respostas de alunos que trabalham como bolsistas de ensino, pesquisa ou extensão, como monitoria e tutoria de educação à distância, dentro da própria UFSC. Dos que responderam que trabalham em outra área, representando um total de 12 alunos, 42\% declarou trabalhar em área comercial, sendo que gestão, sistemas de informação, pesquisa e banco representaram $8 \%$ cada um.

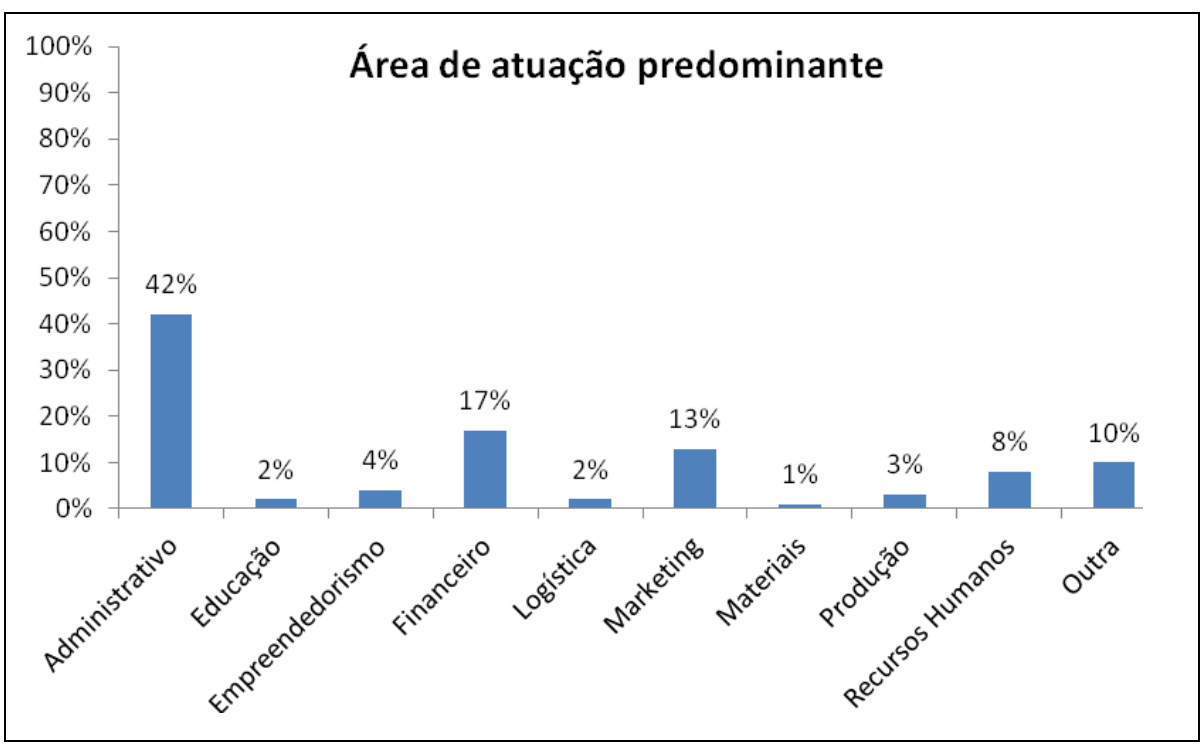

Gráfico 3 Área de Atuação Predominante.

Fonte: Dados primários. 
Quando questionados a respeito da satisfação em relação a sua atividade profissional, a maioria dos graduandos declarou estar satisfeito (62\%), seguidos por aqueles que se declaram muito satisfeitos (27\%). Apenas 11\% declararam-se insatisfeito, e um número ainda menor, muito insatisfeito (1\%).

Apesar disso, ao declararem suas pretensões quanto ao futuro na organização após o término do curso, $46 \%$ responderam que não, ou que provavelmente não permanecerão. $28 \%$ declaram certeza em continuar na atividade, e $26 \%$ responderam que há probabilidades de permanecerem.

A carga horária profissional mais representativa observada foi de 20 horas $(26 \%)$, seguida dos que trabalham 40 horas semanais (22\%). Os que ultrapassam as 40 horas são $15 \%$ da amostra, e apenas 5\% trabalha menos de 20 horas semanais.

Apesar de 37\% trabalhar 40 horas semanais ou mais, a remuneração dos respondentes em geral é relativamente baixa, pois $73 \%$ ganha até três salários mínimos, com a seguinte distribuição: 24\% até um salário mínimo; a maior parte, entre 1 e 2 salários mínimos (28\%); e $21 \%$ é a representatividade dos que obtém ganhos entre 2 e 3 salários. Acima disso, a proporção é bem menor: $7 \%$ percebe entre 3 e 4 salários mínimos; $8 \%$ entre 4 e 5 salários mínimos, e $11 \%$ têm remuneração acima desse valor.

Quanto ao modo de ingressar na organização, 38\% dos respondentes que estão exercendo alguma atividade profissional adquiriram a vaga por meio de processo seletivo, o que pode incluir análise de currículo, dinâmicas de grupo, entrevistas, provas, dentre outros métodos de seleção. O convite, ou indicação, é outra forma bastante utilizada para o ingresso nas atividades, totalizando $31 \%$ dos formandos. Ainda, $10 \%$ dos respondentes passaram em concurso público e 16\% são proprietários ou sócios da organização.

Apenas 36 (30\%) dos 120 declararam ter obtido uma promoção ou ter sido transferido na atual organização que trabalham, sendo que destes 36, 10 (28\%) eram estagiários que foram efetivados, $47 \%$ tiveram uma promoção para um cargo superior e 19\% foram transferidos de forma horizontal. $6 \%$ não declararam a forma como ocorreu esta mudança.

Voltando à análise de toda a amostra pesquisada, incluindo agora os que se dedicam exclusivamente ao curso de graduação, tem-se $43 \%$ que declararam ter uma ajuda de custo adicional, sendo que mais da metade destes (61\%) que não vivem apenas com a remuneração de sua atividade profissional declara receber uma ajuda de custo dos pais. Quando questionados a respeito da natureza desta renda extra $4 \%$ responderam se tratar de pensão, $1 \%$ 
respondeu trabalho informal, e apenas $1 \%$ obtêm renda extra através de investimentos, ações e poupança, o que foi considerado um número baixo, tratando-se de acadêmicos ao final do curso de administração, e que um quarto da amostra total declara a pretensão de seguir carreira na área financeira.

Sobre o perfil acadêmico, apenas $11 \%$ do total afirma já ter cursado ou estar cursando um curso superior ou técnico, sendo que dentre estes, a área com maior representatividade é a de exatas, seguida pela área da saúde.

Quanto à intenção de cursar uma pós-graduação, apenas 14\% do total afirmou a ausência de interesse. Dos $86 \%$ que manifestaram a vontade de continuar os estudos, 46\% coloca que pretende fazê-lo em menos de um ano após a conclusão da graduação, $36 \%$ entre 1 e 2 anos, $10 \%$ entre 2 e 3 anos, $2 \%$ em mais de três anos e $6 \%$ ainda não sabe. O Quadro 8 coloca o tipo de pós-graduação pretendida pelos pesquisados.

\begin{tabular}{|cccc|}
\hline & $\begin{array}{c}\text { Frequência } \\
\text { Absoluta }\end{array}$ & $\begin{array}{c}\text { Frequência } \\
\text { Acumulada }\end{array}$ & $\begin{array}{c}\text { Frequência } \\
\text { Relativa }\end{array}$ \\
\hline Mestrado & 31 & 31 & $24 \%$ \\
MBA & 52 & 83 & $40 \%$ \\
Especialização & 32 & 115 & $24 \%$ \\
Outro & 0 & 115 & $0 \%$ \\
Não sabe & 16 & 131 & $12 \%$ \\
\hline Total & $\mathbf{1 3 1}$ & & $\mathbf{1 0 0 \%}$ \\
\hline
\end{tabular}

Quadro 8 Tipo de pós-graduação - codificada (somente quem pretende cursar). Fonte: Dados primários.

Quanto à área na qual pretendem seguir carreira, é observada uma predominância na área de Marketing, seguida da área Administrativa, Financeira, e pelo empreendedorismo, isto é, vontade de abrir o próprio negócio, conforme é demonstrado no Gráfico 4: Aqui se verifica uma diferença entre a área em que a maioria trabalha e a área que se pretende seguir carreira, já que daqueles que trabalhavam, 42\% compreendia sua área de trabalho como "área administrativa". Uma hipótese é que essa é uma área é a porta de entrada para muitos estudantes, mas que após a graduação, pretende-se trabalhar em algo mais específico, e o grande interesse pela continuação dos estudos após a graduação pode corroborar com essa hipótese. 


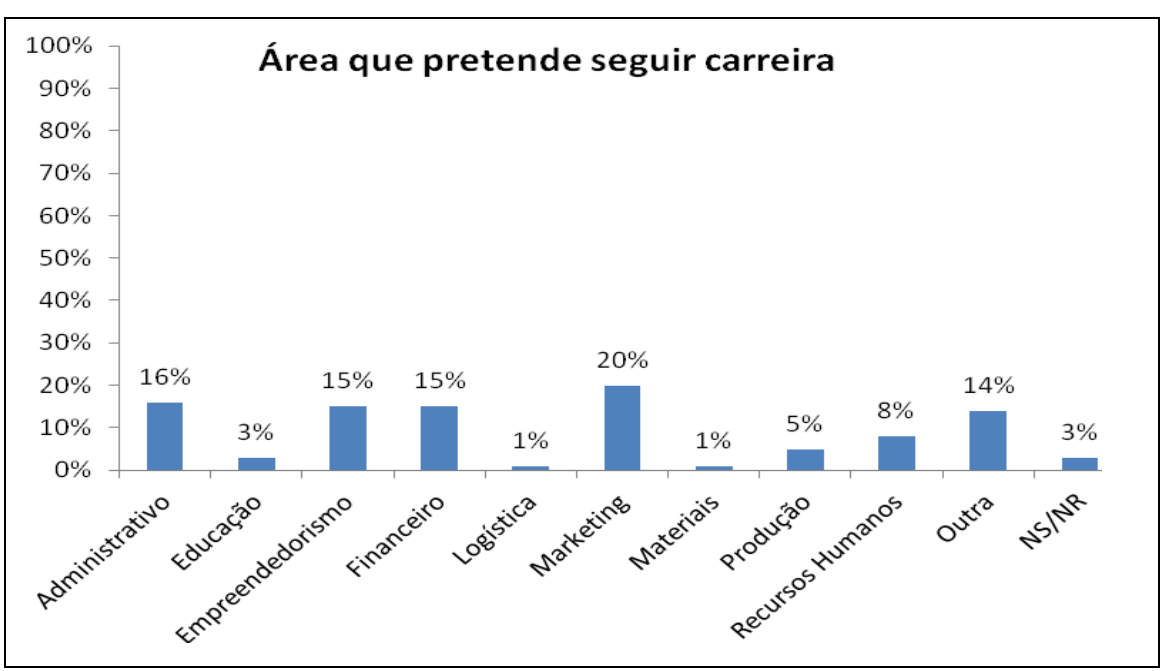

Gráfico 4 Área que pretende seguir carreira.

Fonte: Dados primários.

Em relação a experiências acadêmicas no exterior, $18 \%$ da amostra já vivenciou tal situação, sendo que destes $18 \%, 41 \%$ fez cursos de idioma, $28 \%$ teve uma experiência no ensino médio e $20 \%$, no estudo universitário. As experiências profissionais no exterior são tão representativas quanto as acadêmicas, estando presentes no currículo de também $18 \%$ dos entrevistados. Deste, 37\% fizeram work experience, programa, realizado no período de férias universitárias, permitindo que seja realizada a vivência sem atrasar o curso de graduação, enquanto $11 \%$ dos respondentes afirmam ter tido estágio relacionado ao curso e outros $11 \%$ trabalho formal.

Quanto ao conhecimento de idiomas, 89\% dos respondentes do questionário possuem algum nível de conhecimento em inglês falado. Muitos (26\%), entretanto, têm habilidade para falar apenas inglês básico, enquanto que $25 \%$ possuem inglês intermediário e $24 \%$, possui inglês falado avançado. Apenas 13\% declaram-se fluentes no inglês falado. Quanto à leitura, 94\% conseguem ler textos em inglês em algum nível. Um quarto dos respondentes (25\%) afirmou possuir nível avançado de inglês lido; enquanto que $20 \%$ têm nível básico e $26 \%$, intermediário. $\mathrm{O}$ número de respondentes que indicam ter fluência na leitura aumentou em relação ao inglês falado, passando de $13 \%$ para $22 \%$. O inglês escrito fornece um pouco mais de dificuldade aos respondentes. Um número ainda elevado (91\%) afirma possuir algum nível de conhecimento neste quesito. Entretanto, a fluência foi reduzida a $10 \%$ das respostas, e o nível básico aumentou para $31 \%$.

Em relação ao espanhol, 33\% dos respondentes afirmam não possuir qualquer conhecimento da língua falada. Outros 39\% afirmam possuir um nível básico, o que é 
facilitado pela semelhança do idioma com o português. Apenas $11 \%$ dos respondentes afirmam possuir nível avançado ou fluente de espanhol falado. O número de pessoas com algum conhecimento do idioma aumenta quando este é relacionado à leitura - $28 \%$ dos respondentes afirmam possuir habilidade básica e $26 \%$ o faz no nível intermediário. Outros $17 \%$ afirmam ter conhecimento avançado ou fluente para o espanhol lido. Novamente, a dificuldade aumenta quando em relação à escrita: $42 \%$ afirmam não possuir nenhum grau de conhecimento nesse quesito. Em seguida, 33\% afirmam que possuem conhecimento básico na escrita, e 14\% no nível intermediário. Assim, apenas 10\% dos respondentes têm capacidade de escrita em espanhol entre os níveis avançado e fluente.

\section{CONCLUSÕES}

Após a descrição dos dados obtidos, foram efetuados cruzamentos de dados, que forneceram algumas informações sobre a população pesquisada.

O turno cursado tem forte relação com a atividade profissional, sendo mais representativo para aqueles que trabalham como funcionários: $89 \%$ estudam a noite. Uma hipótese para tal resultado é que o turno da noite tem um horário mais propício para aqueles que trabalham, visto que não exige presença durante o horário comercial. Os bolsistas predominam no período matutino. No entanto, um ponto muito interessante é a porcentagem de respondentes que afirmam não exercer nenhuma atividade profissional ser quase a mesma nos dois turnos: $10 \%$ no turno diurno e $11 \%$ no noturno.

O cruzamento entre carga horária semanal e turno dos que exercem atividades confirma a hipótese de que a proporção de acadêmicos do curso de administração noturno com carga horária superior a 30 horas semanais (68\%) é significativamente superior aos alunos do diurno (32\%). Se ampliarmos para 35 horas, ou mais, a diferença será ainda mais significativa: quase $83 \%$ dos alunos da noite, e apenas $17 \%$ dos da manhã.

Pode-se inferir que, ao longo do curso, os acadêmicos desenvolvem habilidades, podendo aplicá-las em diversos estágios, ou pelo menos, uma ideia do que pretendem fazer ao sair da universidade. Quanto mais se aproxima da formatura, maior a identificação com o que se trabalha, e/ou a necessidade de estabilidade no mercado de trabalho.

O cruzamento relacionado à faixa salarial e o sexo constatou fraca correlação entre as variáveis. Aproximadamente $24 \%$ dos homens declararam ganhar até dois salários mínimos. Entre as mulheres, a proporção foi de $33 \%$. A pequena diferença também é observada nos 
valores superiores: quase $20 \%$ dos homens coloca-se na faixa salarial acima de 4 salários mínimos. A proporção de mulheres nesta faixa de remuneração $(18 \%)$ chega muito perto da porcentagem do sexo masculino, conforme demonstra o Quadro 9 em frequência absoluta:

\begin{tabular}{|cccc|}
\hline & Homens & Mulheres & Total \\
\hline Até R\$678 & 15 & 14 & 29 \\
Entre R\$679 e R\$1356 & 18 & 15 & 33 \\
Entre R\$1357 e R \$2034 & 18 & 7 & 25 \\
Entre R\$2035 e R\$2712 & 6 & 2 & 8 \\
Entre R\$2713 e R\$3391 & 6 & 4 & 10 \\
R\$3392 ou mais & 9 & 4 & 13 \\
NA (não assinalou) & 2 & 0 & 2 \\
\hline Total & $\mathbf{7 4}$ & $\mathbf{4 6}$ & $\mathbf{1 2 0}$ \\
\hline
\end{tabular}

Quadro 9 Faixa salarial x Sexo - codificada (somente quem trabalha). Fonte: Dados primários.

Ainda assim, há maior proporção de mulheres na parte mais baixa da remuneração, e uma proporção menor na parte mais alta. Destaca-se que não está sendo considerada a remuneração por hora trabalhada, sugestão para futuras pesquisas: saber se há diferença nas oportunidades ofertadas ou é uma opção por parte do sexo feminino exercer atividades de menor carga horária. Ressalta-se que não há grande diferença na formação acadêmica, pois se sabe que a população já está no final do curso de graduação, e os que declararam ter um segundo curso foi uma pequena minoria, composta tanto por homens, quanto mulheres.

Este artigo alcançou seu propósito de identificar e analisar o perfil profissional dos prováveis formandos do curso de Graduação em Administração da UFSC, nos semestres 2013/2, 2014/1 e 2014/2. Para tanto foi realizada uma pesquisa descritiva, predominantemente quantitativa, com base em uma amostragem não-probabilística, com um método de comunicação estruturado não disfarçado, questionário estruturado autopreenchível para aquisição de dados primários, distribuído entre os elementos da população da pesquisa. Verificou-se, que grande parte dos respondentes (78\%), já está inserida no mercado de trabalho. Além disso, foi possível identificar que, dentre os que não estão exercendo atividades profissionais no momento, o motivo predominante não é o fato de não encontrar um emprego ou estágio, mas a falta de tempo e o interesse em se dedicar principalmente às atividades acadêmicas.

Dentre os que exercem atividades profissionais, 38\% obtiveram sua vaga através de processo seletivo. Este fator indica que há vagas disponíveis no mercado, divulgadas em 
etapas de processos de recrutamento. Ou seja, o mercado está absorvendo não só profissionais com experiência na área, mas também acadêmicos, em sua maioria, inexperientes. Destaca-se, entretanto, a predominância da realização de atividades na área Administrativa, normalmente indicada nos processos de seleção para encobrir atividades rotineiras e operacionais, e percebe-se que a maioria não pretende seguir nesta área.

A remuneração de $28 \%$ dos respondentes que exercem alguma atividade profissional se encontra entre 1 e 2 salários mínimos. É a faixa de remuneração predominante. Recebem entre 3 e 4 salários mínimos, apenas 7\%, seguido dos que ganham de 4 a 5 salários mínimos, (8\%). Percebe-se que não é uma distribuição homogênea nem contínua da faixa salarial. Conforme esperado, a maioria dos que trabalha em uma carga horária mais elevada recebem maior remuneração absoluta por mês. Ainda assim, pela ausência de dados exata de horas de trabalho e remuneração recebida, não é possível estabelecer a quantidade relativa de remuneração por hora trabalhada, e se há grande dispersão entre os valores.

Grande parte dos acadêmicos pesquisada não demonstra ser independentes. Mais da metade reside com a família, e um número alto possui ajuda de custo adicional à remuneração de sua atividade profissional, sendo a mesada fornecida pelos pais a resposta de maior incidência.

As áreas mais demandas para dar prosseguimento à carreira são Marketing, Administrativo, Financeira e atividades de empreendedorismo. A exigência de aprimoramento constante, pelo mercado de trabalho, parece estar presente na mente dos potencias formandos. A grande maioria pretende continuar seus estudos com a realização de uma pós-graduação. E, além disso, $70 \%$ pretendem fazê-lo em até 2 anos após a formatura da graduação. A preocupação com o preparo para o mercado de trabalho é refletida, também, nos dados referentes a conhecimento em línguas estrangeiras. O índice de quem afirma possuir nenhum conhecimento em inglês é baixo ( $10 \%$ falado, $5 \%$ lido e $8 \%$ escrito). A ausência de disciplinas de línguas no curso de graduação em Administração da UFSC indica que, para atingir os graus de conhecimento levantados nessa pesquisa, os alunos têm buscado cursos extracurriculares, visando o aperfeiçoamento e criação de diferenciais competitivos. O maior grau de conhecimento de inglês pode ser explicado pela quantidade de respondentes que afirmaram ter realizado atividades acadêmicas ou profissionais no exterior.

Dentre as principais dificuldades da pesquisa, destacou-se a ausência de uma listagem oficial com os nomes dos prováveis formandos 2013/2, 2014/1 e 2014/2 e a dificuldade em 
encontrar os graduandos da última fase do curso, que refletiu no número de questionários aplicados, com um percentual menor de respondentes da última fase.

A determinação da provável formatura é uma variável sazonal, uma vez que, a cada semestre, os elementos que fazem parte da população-alvo desta pesquisa podem não estar mais inclusos nela; assim como estudantes de outras fases podem ter adiantado disciplinas nesse semestre, passando a figurar entre os prováveis formandos do período. Recomenda-se a repetição desse estudo anualmente, para que possam ser traçadas tendências e para que se possam observar variações do perfil profissional dos alunos que estão próximos à conclusão do curso. Também pode ser interessante realizar uma pesquisa com esse mesmo publico, sobre sua área de atuação, nível salarial, satisfação, dentre outros fatores pesquisados no estudo atual, a fim de realizar uma comparação sobre seu desenvolvimento e suas pretensões.

\section{REFERÊNCIAS}

BARBETTA, Pedro Alberto. Estatística aplicada às ciências sociais. Florianópolis: Ed. Da UFSC, 2011. 7. Ed.

CFA - CONSELHO FEDERAL DE ADMINISTRAÇÃO. História da Administração. Disponível em: <http://www.cfa.org.br/administracao/historia-da-profissao >. Acesso em: 30 out. 2013.

Pesquisa Perfil 2011. 2011. Disponível em: <http://www.cfa.org.br/servicos/ publicacoes/pesquisa-perfil-2011.pdf/view>. Acesso em: 01 out. 2013.

CRA-SP - CONSELHO REGIONAL DE ADMINISTRAÇÃO DE SÃO PAULO. Áreas de atuação do administrador. Disponível em: $<$ http://www.crasp.

gov.br/crasp/WebForms/interna.aspx?secao_id=153>. Acesso em: 1 out. 2013.

DEPARTAMENTO DE CIENCIAS DA ADMINISTRAÇÃO. Plano Estratégico.

Disponível em: $\leq$ http://portal.cad.ufsc.br/plano-estrategico/>. Acesso em: 01 out. 2013.

G1. Educação. Sisu 2015 teve quase 2,8 milhões de inscritos. 2015. Disponível em http://g1.globo.com/educacao/noticia/2015/01/sisu-2015-teve-quase-28-milhoes-de-inscritosresultado-sai-nesta-segunda.html. Acesso em 04 de fev. de 2015.

INEP - INSTITUTO NACIONAL DE ESTUDOS E PESQUISAS EDUCACIONAIS. Inep divulga dados do Censo Superior. 17 out. 2012a. Disponível em:

$<$ http://portal.inep.gov.br/visualizar//asset_publisher/6AhJ/content/inep-divulga-dados-docenso-superior?redirect $=\mathrm{http} \% 3 \mathrm{~A} \% 2 \mathrm{~F} \% 2 \mathrm{Fportal}$.inep.gov.br\%2F>. Acesso em: 30 out. 2013.

Resultados do Enade 2012. 2012b. Disponível em: < http://portal.inep.gov.br/ enade/resultados>. Acesso em: 30 out. 2013. 
MATTAR, Fauze Najib. Pesquisa de Marketing 1. 6. ed. São Paulo: Atlas, 2005.

MEC. Ministério da Educação. Administração e direito são os cursos com mais inscrições. 2015. Disponível em:

http://portal.mec.gov.br/index.php?option $=$ com_content\&view $=$ article\&id=20110\%3Aadmini stracao-e-direito-sao-os-cursos-mais-procurados-ate-o-momento\&catid=410\&Itemid $=86$.

Acesso em 04 de fev. de 2015.

PRAHALAD, C. K. E HAMEL, GARY: The core competence of the corporation. Boston: Harvard Business Review, maio-junho 1990, pp. 79-91.

ROPÉ, FRANÇOISE E TANGUY, LUCIE (ORGS.): Saberes e competências - o uso de tais noções na escola e na empresa. Campinas: Papirus, 1997.

RUF - Ranking Universitário Folha. As 10 melhores universidades. 2013. Disponível em: $<$ http://ruf.folha.uol.com.br/2013/>. Acesso em: 29 out. 2013.

SILVA, Flora Moritz da; FINGER, Luciane; VITAL, Juliana Tatiane. Análise do Perfil Profissional dos Potenciais Formandos do Curso de Administração da Universidade Federal de Santa Catarina. In: VIII Colóquio Internacional sobre Gestão Universitária na América do Sul, 2008, Asunción. La Gestión de la Educación Superior Universitaria como Derecho Humano y Bien Público Social, 2008.

SOUZA, Irineu Manoel de Formação Profissional IV. Florianópolis, 2013, 78p. Apostila da disciplina Formação Profissional IV do Curso de Graduação em Administração da Universidade Federal de Santa Catarina - UFSC.

UNESCO. ABRAMOVAY, Miriam; CASTRO, Mary Garcia (Coord.) Juventude, juventudes: o que une e o que separa. Brasília: Edições UNESCO, 2006. Disponível em: $<$ http://www.dominiopublico.gov.br/pesquisa/DetalheObraForm.do?

select_action=\&co_obra=64654>. Acesso em: 01 out. 2013.

ZIKMUND, William G. Princípios da pesquisa de marketing. São Paulo: Pioneira Thompson Learning, 2006. 